\title{
EENIGE OPMERKINGEN OVER DE SURINAAMSCHE NEGERTAAL
}

\author{
Door
}

\section{A. J. MORPURGO}

Een maand of twee geleden kreeg ik het keurig uitgegeven boek DJUKA van Prof. Dr. Morton C. Kahn in handen en reeds na de eerste bladzijden ervan vluchtig te hebben doorgelezen boezemde het mij zooveel belangstelling in, dat ik het als een roman verslond in korten tijd.

Bij de lezing trof mij echter herhaaldelijk, dat de negertaal, die daarin kwistig is gebruikt, op menig punt aanleiding geeft tot op- en aanmerkingen, die, naar ik mij voorstel, ook voor anderen nut kunnen hebben.

In het Februari nummer (1931) van de W. I. Gids merkt de schrijver immers van zichzelf op, dat hij de negertaal ,fairly well” heeft leeren spreken en ofschoon hij daarvan soms inderdaad blijken geeft, komen er zoowel bij de zinsvorming als het woordgebruik en de vertaling meermalen vragen op bij den lezer, die tegenover deze taal niet als vreemde, maar als geboren Surinamer staat.

Reeds vaak gaf het gebruik der negertaal door buitenlanders aanleiding genoeg tot het plaatsen van de opmerkingen, die hier zullen volgen, doch, zooals het gewoonlijk gaat, wanneer men door velerlei bezigheden van uiteenloopenden aard wordt in beslag genomen, er komt zoo licht uitstel, dat afstel dreigt te worden.

In Deel I van zijn Handboek der Nederlandsche Taal (L. C. G. Malmberg, Nijmegen, 1913) zegt Prof. Dr. Jac. van Ginneken S. J. op bladzijde 261: „Zoo is er dan in onze West-Indische koloniën, hoewel er de regeeringstaal natuurlijk Nederlandsch is, slechts een betrekkelijk zeer klein groepje, dat Nederlandsch spreekt en denkt. In Suriname kennen de meeste inwoners toch alleen Negerengelsch, en ook de blanken moeten er zich goedschiks kwaadschiks tegenover de kleurlingen van bedienen, als zij willen worden verstaan". 
Deze zinsneden, voorkomend in den aanhef van het Negende Hoofdstuk, waarin het West-Indisch behandeld wordt, waren bij de verschijning van het boek in 1913 reeds niet juist meer, daar het Nederlandsch toen reeds voor verreweg de meesten de voertaal was en zeer velen, die het slechts gebrekkig konden spreken, het niettemin heel goed konden verstaan.

Thans zal men buiten de alleroudsten van dagen niet licht menschen meer vinden, voor wie het Nederlandsch een vreemde taal kan worden genoemd.

Dit voor zooveel de Surinamers zelven betreft.

Onder de Aziaten, die het grootste deel der niet-Surinaamsche bevolking uitmaken, zal men onder de Britsch-Indiërs een hoog percentage vinden, dat het Nederlandsch uitstekend beheerscht en ook onder de Chineezen is het cijfer in stijgende lijn.

Men kan gerust zeggen, dat de generatie, die hier geboren is en daardoor - als gevolg van den leerplicht - het onderwijs genoot, zeer goed vertrouwd is met het Nederlandsch.

Vanzelf sprekend heeft deze omstandigheid haar invloed zeer sterk doen gelden en in de negertaal der stadsbewoners en van die districtsbewoners, waar het onderwijs lang genoeg heeft doorgewerkt en waar er bovendien aanraking was met Nederlandschsprekenden, werden tal van woorden verdrongen door nieuwe, die gevormd waren naar Nederlandsche.

De opmerking terzake, welke van Ginneken maakt op blzd. 262 van zijn evengemeld Handboek, is dan ook juist in hare algemeenheid, doch of zijn voorbeelden ook ten volle juist zijn, betwijfel ik. Zoo b.v. zal men niet hooren van een Surinamer: „mi denki" in plaats van „mi mémbre”, zooals hij aangeeft.

Scherp onderscheiden staan naast elkaar dinki (denken), mim(b)ré (herinneren) en prakseeri (nadenken).

Het gezag van schrijvers doet uitspraken omtrent de taal door buitenlanders, die haar aanleeren, hardnekkig aanhangen en als vanzelf sprekend gevolg vindt men ze voortdurend herhaald en toegepast in schrifturen over Suriname, waardoor het tenslotte moeite kost het geloof ingang te doen vinden, dat de een of andere onjuistheid erin is vervat.

Ook het gebruik der taal door Morton Kahn stelt deze kwestie aan de orde.

Daargelaten dat zijn spelling niet consequent wordt volgehouden op het gehoor, is deze hier en daar niet in overeenstemming met de klankwaarde der uitspraak, die zij moet uitbeelden.

Als hij b.v. "fissee” schrijft voor visch, geeft hij niet de con- 
stant-algemeene uitspraak weer, doch waarschijnlijk een sporadisch-individueele, wijl bij de gewone uitspraak: „fisi” beide $i$-klanken dezelfde klankwaarde hebben. Door de spelling van Morton Kahn wordt de klankwaarde kort-lang. In werkelijkheid is zij kort-kort. Onjuist is bij hem een meermalen voorkomende omzetting van $a$ in $o$, welke mij op bl. 77 van zijn boek deed onderstellen, dat er eenvoudig een bekend gebrek bij de beluisterden in het spel was. Het geldt daar n.l. een liedje, dat hij als volgt opteekent:
Cony mong,
Koni man
Cony mong,
Koni man
Dede na leeba.
Dédé na liba

Bij zangers komt vaak voor, dat zij door verkeerden mondstand de klankvorming in het gedrang brengen en van een $a$ een gewestelijken $a o$-klank maken. Dit kon misschien in het onderhavige geval zoo sterk zijn geweest, dat „Koni man” vervormd werd tot „Koni mon”, doch deze onderstelling kon bezwaarlijk gehandhaafd worden als daarnaast werd gelegd een gesproken voorbeeld van blzd. 72, waarin de naam des schrijvers zelf een rol speelde.

Er werd n.l. tijdens zijn reis een kreek naar hem gedoopt en volgens hem genoemd: „Datra Cong Creekee”, terwijl de lezer verwacht, dat er sprake zou zijn van „Datra Kan Kriki”.

Een verklaring voor deze voortdurend terugkeerende klankvervorming heb ik niet kunnen vinden, of ik moet aannemen, dat zij steeds van denzelfden beluisterde afkomstig was, in welk geval zij ten hoogste constant-individueel kon worden geacht.

Eigen ervaring in het beluisteren van de taal langs nagenoeg alle rivieren, waaraan negerstammen wonen, terzijde schuivend, legde ik de gevonden voorbeelden uit Kahn's boek voor aan missionarissen, die jarenlange ervaring hebben met Boschnegers en aan den heer W. E. van Lier, oud-posthouder bij de Aucaners, doch voor allen was deze omzetting even vreemd.

In het stads-Negerengelsch is er evenmin sprake van deze klankverandering, hetgeen terloops zij opgemerkt, daar het bij mijn aanteekeningen uitsluitend gaat over de taal bij Boschnegers waarvan bekend mag worden ondersteld, dat zij verschilt van het stads-Negerengelsch; de tekst der taal bij Morton Kahn is doorgaans echter stads-Negerengelsch.

Om de aangehaalde voorbeelden meer relief te geven, mogen er nog eenige volgen: 


$\begin{array}{ll}\text { con con dree } & \text { voor kankantri } \\ \text { okra } & \text { voor okro } \\ \text { koru } & \text { voor karu }(\mathrm{u}=\mathrm{oe})\end{array}$

Herhaaldelijk voorkomende spelling, die vraagteekens doet zetten is de Eng. ee voor veel $i$-klanken, die den Surinamer als kort in het gehoor liggen, doch, door $e e$ voorgesteld, lang worden.

Ook al brengt men het sleepend spreken der Boschnegers in rekening, dan staat men nog voor een spelling, die met de werkelijkheid niet overeenstemt, want voor „méki” (maken) vindt men bij Kahn „makee”, waarin de eind- $i$ verlengd wordt, ofschoon men bij Aucaners hier vrijwel heelemaal geen $i$ hoort, maar veeleer twee korte open $e$-klanken: „méké”.

Zoo is er meer, doch met het bovenstaande is er, meen ik, ten aanzien van de spelling voldoende opgemerkt.

Een eigenaardig geval van verkeerde vertaling, waaruit duidelijk blijkt, voor welke moeilijkheden een vreemdeling staat bij nasporingen onder natuurvolken, levert „timbeh”, waarvoor als synoniem wordt gegeven „sanni” met als vertaling „wood carvings".

„Timbeh" (timbé) herinnert natuurlijk aan het Engelsche timber, voor timmerhout, doch het moet wezen „timbré”, van timmeren.

"Sanni" is echter het gewone woord voor ding(en).

Bij zijn bezoeken aan Boschnegerdorpen lichtten de bewoners elkaar vaak in met de mededeeling; dat de bakra „wanni bai sanni”, (woordelijk: „wil koopen dingen”) waaruit hij afleidde, dat sanni specifiek houtsnijwerk beteekent.

De vergissing is verklaarbaar.

Sanni beteekent ook in dit verband niets anders dan ding(en) en zou ook gebruikt worden, als er iets anders te koop werd gevraagd, b.v. aardvruchten.

„Bai sanni” en „seeri sanni” zijn de gebruikelijke uitdrukkingen voor koopen en verkoopen van.... dingens".,,

In 18-karaats Surinaamsch Nederlandsch zal men ook intellectueelen en vooral kinderen „erop kunnen betrappen, dat zij spreken van „dingen”, „dinges”, of „dingens” koopen, of verkoopen, onverschillig of het manufacturen geldt of provisiën, of wat dan ook. 
Dit gebruik in het Surinaamsch Nederlandsch wijst erop, dat het Nederlandsch en de negertaal elkander wederkeerig beïnvloeden, zooals trouwens heel natuurlijk is. Doch tevens bewijst het, dat „sanni" niet specifiek als houtsnijwerk kan vertaald worden, zooals de schrijver uitdrukkelijk doet.

In zijn Index verwijst hij voor een definitie van „sanni” naar bladzijde 194, waar hij schrijft: „All of the wood carvings, collectively known as sanni or timbeh...."

Iets dergelijks vindt men ook bij de vertaling van "switi moffo" door ,good eating i.c. sweet mouth".

Het juiste woord voor switi mofo (s'stimofo) is toespijs.

Alle toespijs, onverschillig of zij bij warme kost of bij de boterham gebruikt wordt, heet swit mofo.

Zoo is ook elke morgendrank ter ontnuchtering „fajawatra", (heet water) hetzij deze koffie is, of thee, of cacao; warm of koud.

Bij de medicijn-bereiding maakt de schrijver op blz. 155 melding van het gebruik van bladeren, afkomstig van een plant, „known as pekein fol caca" welken naam hij tusschen haakjes vertaalt als „little rooster”, kleine haan.

Hier heeft een verwisseling plaats, die eenigszins grappig aandoet.

Den schrijver heeft daarbij kakaforoe of kakafoloe voor oogen gestaan, dat inderdaad haan beteekent. De omzetting der samenstellende deelen leveren echter een samengesteld zelfstandig naamwoord op, dat geheel iets anders beteekent, n.l. uitwerpselen van kleine vogels.

Dergelijke namen komen meer voor in de natuurlijke historie der negers.

Een bekende pepersoort draagt den plastischen naam van alatakaka pépré, aangezien de vruchtjes in uiterlijk sterk lijken op uitwerpselen van de rat.

Het gebruik van persoonlijke voornaamwoorden en de vertaling van het vervoegde werkwoord leveren ook vaak moeilijkheden op.

Kort bij elkaar vindt men op bladzijde 167 in de lijst van zinnen tweemaal "Ah" vertaald als eerste pers. enkelvoud, ofschoon het derde pers. enkelvoud is.

„Ah go kissi fissi” wordt weergegeven als „I go to catch fish”. "Tamara Ah sa go honti" wordt weergegeven als „Tomorrow I shall go hunting".

West-Indische Gids XIV 
Er is geen sprake van een eersten persoon in deze zinnen. De eerste persoon enkelvoud is $M i$, nooit $A$.

In den eerst-aangehaalden zin geeft het vervoegde werkwoord een vaak voorkomend voorbeeld van verkeerde vertaling.

"A go kisi" is duidelijk perfectum, doch wordt vertaald als praesens.

Deze fout komt zeer dikwijls voor in het boek en ook bij buitenlanders, zelfs die jaren hier gevestigd zijn.

Bij de beluistering ontgaat hun blijkbaar het subtiele, doch zeer duidelijke onderscheid tusschen
A go
$\mathrm{Hij}, \mathrm{zij}$, het is gegaan

en $\mathrm{Ai}$ go

$\mathrm{Hij}$, zij, het gaat

in welken laatsten vorm "Ai" een samentrekking is van „A dé”.

Slechts in zeer weinig gevallen wordt de praesens gevormd zonder gebruikmaking van het hulpwerkwoord de (zijn). De regel is, dat het onontbeerlijk is en wat wij als een praesens voelen, zou dan eigenlijk een gérondif zijn. (Hij is gaande).

Mi loekoe, mi takki, mi sribi zijn alle voltooid tegenwoordige tijden, geen onvoltooide.

Daarnaast staan uitzonderingsvormen als mi wanni, mi sabi, die wèl onvoltooid tegenwoordige tijden zijn.

Voor de vorming van den voltooid tegenwoordigen tijd wordt hier bin (vervoegde vorm van dé) ingelascht: $\mathrm{mi}$ bin wanni, mi bin sabi, waarbij dan uit het zinsverband moet blijken, of men een perfectum heeft, of een imperfectum (onvoltooid verleden tijd).

Gelijk hiervoor reeds opgemerkt, komt zoowel bij den schrijver als bij buitenlanders, die hier de taal spreken, zeer veel, bijna als regel, voor, dat de perfectum-vorm gebruikt wordt, waar een praesens bedoeld is.

Voor de beteekenis brengt dit weleens zulke veranderingen mee, dat misverstand, begripsverwarring niet kunnen uitblijven.

Hierbij kan ik het laten.

Volledigheid streefde ik geenszins na.

Was dit wel het geval, dan zou ik naast de enkele aanmerkingen, die ik plaatste er meer moeten geven en ook ruimte moeten maken voor de vermelding van voorbeelden, die wijzen op een ernstige poging om zuiver te beluisteren en zuiver weer te geven, welke poging soms voortreffelijk slaagde, zoo b.v. op blzd. 45 „fie you tang", (hoe gaat het) dat beter het gesprokene uitbeeldt dan ons gebruikelijk „fa joe tan”. 
Aan de waardeering voor het boek, dat niet bedoeld is als een geschrift over de taal der bestudeerde djoekas, behoeven de aanmerkingen intusschen geen afbreuk te doen.

Voor de uitspraak der schrijfwijze, welke ik volg, diene als sleutel: $1 . i$ in gesloten lettergrepen en $e ́$ klinken als de korte $i$ in gesloten lettergrepen in het Nederlandsch. (pit);

2. $i$ in open lettergrepen klinkt als korte ie (kier);

3. ee beantwoordt aan onze $e e$ in "teer";

4. $i e$ is lang en heeft de klankwaarde als in "dier".

In den titel spreek ik van negertaal, wijl de taal der Boschnegers, waarover het in hoofdzaak gaat, nog minder dan die van de stadsnegers wordt geteekend door den algemeen gebruikten term „Negerengelsch”.

Ten aanzien van de spelling zij terloops opgemerkt, dat ik de spelling van Dr. Kahn, die natuurlijk met Amerikaansche klankvoorstellingen werkte, steeds verlaat, waar ik zelf de negertaal aanhaal. De $n g$ aan het eind van woorden, welke hij gebruikt, schrijf ik als $n$, daar de eind- $n$ in den regel nasaal is, behoudens schaarsche uitzonderingen. o.m. in klank nabootsingen; en bovendien, wijl de $n g$ niet volkomen de nasale $n$ dekt.

Op bladzijde 164 van zijn boek (DJUKA) zegt Morton Kahn in het hoofdstuk Djuka Talk: „The only difference between the Bush Negro's talkee-talkee and its use by the other natives of the colony is that the former have many words peculiar to themselves, such as the names of their gods and their implements".

Kahn poneert hier dus de stelling, dat het verschil tusschen de negertaal (Negerengelsch) bij de Boschnegers en anderen, die haar spreken, uitsluitend is gelegen in het woordgebruik en wel in dien beperkten zin, dat de Boschnegers woorden gebruiken, die de anderen niet hebben in hun woordenschat.

Dit lijkt mij niet goed gezien.

Reeds op grond van het feit, dat omgekeerd de anderen woorden hebben, die men bij den Boschneger niet zal hooren.

Bestond het verschil slechts in deze afwijkende woordenlijsten aan twee zijden, dan zou er weinig reden zijn dit onderwerp afzonderlijk te bespreken.

Er is echter meer en dieper gaand verschil. En daarop te wijzen is het doel van dit artikel.

Morton Kahn noemt slecht één punt van verschil: het woordgebruik. Dit als nummer 1 teekenend vul ik het lijstje aan:

2. verschil in uitspraak, 
3. verschil in woord-accent,

4. verschil in zinsmelodie.

De punten 3 en 4 eerst afwerkend, teeken ik kort aan, dat zoowel woord-accent als zinsmelodie duidelijk den Boschneger, den plantage-neger en den stadsneger van elkaar onderscheiden.

Het woord bakra (blanke) heeft bij den stadsneger twee korte $a$-klanken en het accent valt bij hem op de laatste lettergreep.

Bij den Boschneger klinkt het als bâk a, waarbij de eerste $a$ verlengd wordt en het accent daarheen verschuift.

De zinsmelodie wordt, mede in verband daarmede, anders en de binding der woorden aan elkaar geschiedt anders. Geschreven vertoont een zin betrekkelijk weinig afwijking; het is een kwestie van beluistering.

Van meer beteekenis is het verschil in uitspraak.

Dit betreft zoowel vocalen als consonanten.

Sommige vocalen worden eigenaardig verlengd en sommige consonanten vertoonen typische afwijkingen, die onmiddellijk opvallen.

Het sterkst vindt men dit wellicht bij $l$ en $r$.

Naast elkaar vindt men b.v. foeloe en foeroe voor veel.

Achterlijke oudjes buiten beschouwing latend kan men met zekerheid zeggen, dat de stadsneger hier de $r$ zal laten hooren en de Boschneger en de ongeschoolde plantage-neger de $l$.

De uitspraak foeloe wordt geschat als ,plat”. En tien tegen een, dat de stadsneger, die zal spreken van foeloe, wordt uitgelachen en spottend plantage-neger wordt genoemd.

De consonanten $l$ en $r$ spelen in de kringtalen een zeer belangrijke rol, die met deze enkele opmerkingen geenszins volledig is geteekend.

Om er nog een typisch voorbeeld van te noemen, wijs ik op de vervanging van $l$ door $r$ in sommige woorden bij de stadsnegers, waaruit duidelijk het milieu blijkt.

Men kan die beluisteren bij vrouwen uit de heffe des volks, dames van de vlakte, die zich ordinair aanstellen of kijven en in plaats van loekoe (kijken), lépi (rijp), die ook bij den Boschneger onveranderlijk met $l$ voorkomen, zeggen: roekoe en répi.

Stadsnegers, die zich rekenen tot de fatsoenlijken, zullen deze consonant-verwisseling nooit toepassen.

De kringtaal is hier onfeilbaar kenmerk voor peil van beschaving en milieu.

Steeds terugkeerend is ook bij Boschmegers de behandeling van de $r$ in het stads-Negerengelsch, waar zij dat spreken. 
Onze begin- $r$ is bij hen gewoonlijk $l$ : rédi, rood, is bij hen lédi; Ook tusschen twee klinkers zal de $r$ van den stadsneger bij den Boschneger in den regel $l$ zijn.

Bij scherpe beluistering zal men eigenlijk nooit een $r$ hooren bij den Boschneger. Waar hij niet als $l$ klinkt, zal hij hoogstens als een zeer vage huig- $\boldsymbol{r}$ doorkomen, of heelemaal niet gehoord worden. Ouderlingen van het dorp, gran soema, zal hij uitspreken als g'ân sama.

Reeds de behandeling der $r$-klanken doet den Boschneger zich verraden door zijn spraak, waardoor hij onmiddellijk te herkennen is.

Duidelijke aanwijzing geeft ook de $g$.

In de verbinding $n g$, die de stadsneger uitspreekt als in het Nederlandsch, laat de Boschneger gewoonlijk de Fransche $g$ hooren. Voor lang zegt de stadsneger langa, dat als een Nederlandsch woord wordt uitgesproken. De Boschneger zal de $n$ nasaliseeren en de $g$ de klankwaarde geven van de $g$ in "garçon”.

Dit voor zooveel consonanten betreft.

$\mathrm{Bij}$ vocalen doet zich de eigenaardigheid voor, dat de Boschneger er vele verlengt, die bij den stadsneger kort zijn.

Voor broek zegt de stadsneger broekoe, met twee korte oe-klanken.

Als de Boschneger dit woord moet uitspreken, zegt hij b'oekoe, waarin de $r$ wordt weggemoffeld naar de keel en de eerste $o \boldsymbol{e}$ sleepend wordt verlengd, tot ongeveer het dubbele.

Over het algemeen zal hij in woorden, waarin dezelfde vocalen voorkomen, in twee op elkaar volgende lettergrepen, een daarvan de eerste, verlengen.

Er zijn uitzonderingen, doch deze bevestigen immers den regel?

Een zeer belangwekkend hoofdstuk opent de term ,talkee-talkee" waarmede de Negertaal wordt aangeduid.

In mijn vorig artikel schreef $\mathrm{ik}$, dat ik den term Negerengelsch liever niet gebruik. De reden gaf ik daarbij aan.

De Surinamer duidt zijn landstaal echter steeds aan als Negerengelsch en in de landstaal spreekt hij van ningré-tongo, en meer nog, kortweg: ningré. (Tak' ningré, spreek Negerengelsch).

Buitenlanders gebruiken zelden dezen term.

De Franschen spreken van Le takkitakki.

Engelschen en Amerikanen spreken van talkee-talkee. 
Nederlanders spreken vaak van takkitakki.

Wij, Surinamers, doen dit nooit.

Het woord takkitakki (taktakki) is ons wel bekend, doch voor ons dekt het een ander begrip: gebabbel, gezeur. (No taktakki so, zeur niet zoo).

Aan dergelijke woorden, die een herhaling zijn van een bestaand woord is de taal rijk. In de spreektaal wordt veelal den eersten keer het woord ingekort. Den tweeden keer wordt het voluit gesproken.

Men vindt eronder werkwoorden, substantieven, adjectieven.

1. Werkwoorden. Deze kunnen o.m. zijn:

a. onomatopoeën: srobosrobo, sloffen; tjoekoetjoekoe, den mond spoelen.

b. frequentatieven: hari, trekken; har'hari, aldoor trekken; nakki, slaan; naknakki, voortdurend slaan; béti, bijten; bét'béti, voortdurend bijten, of op verschillende plaatsen bijten. In het laatste voorbeeld kan men misschien ook een intensief willen zien.

c. intensieven : firi, voelen; fir'firi, betasten; djompo, springen; djompodjompo, huppelen.

d. soms geven werkwoorden, gevormd door een dergelijke herhalingsfiguur een verzwakking aan van het grondwoord: lobi, wrijven, lob'lobi, licht smeren; soekoe, zoeken; soek'soekoe, vluchtig zoeken;

e. soms verandert door de herhaling de beteekenis: méki, maken; mékméki, zich aanstellen; wakka, loopen; wakkawakka, slenteren, zwieren.

2. Substantieven. Deze kunnen zijn:

a. onomatopoeën: teptep, goedkoope slof met houten zolen, die onder het loopen een geluid geeft als door den naam uitgedrukt; brinbrin, bak, of trommel van dun blik, die hij het neerzetten ongeveer brin "zegt"; siensien, groote trom, of ook insect, dat zijn eigen naam noemt; woenwoen, groot insect, dat zijn naam noemt, door de trillende vleugels n.l. - ook maanvormige bromklep aan vliegers; pakkapakka, motor(boot); tikotiko, de hik; paipai (kindertaal), klappen, pak slaag.

b. de herhaling geeft soms een verzwakking te kennen: rédi, rood; rédirédi, roodachtig; met alle kleuren kan men deze samenstelling maken ter uitdrukking van een verzwakking.

c. door de herhaling krijgt men soms een geheel andere beteekenis, die soms, maar niet altijd, in verband te brengen is met het grondwoord;

Met verband: groen, groen; groengroen, lagere plantensoort, 
die op vochtige plaatsen groeit en zich aan den binnenwand van waterputten vastzet; witti, wit; wit'witti, witte hoofdroos of ook een bekende vischsoort, die blank is; krassi, jeuken; kras' krassi, schurft; broko, gebroken; brokobroko, versleten; moi, mooi; moimoi, opschik, versiering; lau, gek; laulau, beuzelachtig; bron, branden of gebrand; bronbron, aangebrand onder uit den pot (b.v. van rijst; bron-bron van masoesa-rijst geldt als een lekkernij); séki, schudden; sék'séki, opschudding; bari, roepen, schreeuwen; ba'bari, lawaai.

3. Adjectieven. Hierbij kan een indeeling gevolgd worden als bij de substantieven. Daarenboven komen sommige werkwoordelijke vormen als adjectief voor in natuurlijk dezelfde onderafdeeling, als die, welke zij onder werkwoorden bezetten.

Morton Kahn doet de taal recht wedervaren, waar hij haar schilderachtig noemt en muzikaal.

Dat is zij inderdaad.

En zij moge, wetenschappelijk beschouwd, in menig opzicht arm genoemd worden, aan bekoring is zij rijk, waar zij gesproken wordt door een, die haar goed beheerscht en haar weet te gebruiken als instrument voor de uitbeelding van naïeve verbeeldingen.

Daar spelen de herhalingsfiguren en klanknabootsingen, die er los tusschen geworpen worden, een rol bij, ons voerend in een primitieve gedachtenwereld.

Als men op scholen, in de lagere klassen, kinderen laat vertellen, of men laat volwassen negers hun sproken en sagen voordragen, - de uitdrukkingswijzen zijn gelijk.

Beiden bedienen zich van klankschilderende effecten, doordat zij elke handeling, ook die, welke geluidloos is, in een klankencombinatie weten om te zetten bij de dramatiseering van hun stof.

Bij beiden klotst de zee: patsjââ; gaapt een kuil: wââ; valt men van de trap: briebra(b); klinkt een klap: pai, of peei en een kus pjow; holt het paard: plakataplakata en marcheert een compagnie: gám-gam, gám-gam (accent op de eerste lettergreep); plonst een steen in het water: tjoeboen; en dreunt het kanon: die bien, nog lang nagalmend.

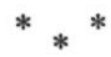

De herhalingsfiguur treedt zoo vaak op, dat buitenlanders 
in de verleiding komen ze zelf te maken of (verkeerd) te gebruiken.

Slechts weinigen hunner gelukt het de atmosfeer van ons tropenland en onzen volksaard te doorgronden en onder de weinigen, die erin slaagden zich bij hun poging daartoe te onderscheiden, neemt m.i. Morton Kahn een plaats vooraan in.

Bij alle aanmerkingen, die zijn behandeling der taal in dit boek van 12 hoofdstukken deed maken, blijft het een eerbiedwekkend stuk werk, dat heel bizondere waardeering verdient.

$\mathrm{Na}$ lezing ervan heb ik mij afgevraagd, waarom een Amerikaan de zee moest oversteken om dit boek te schrijven na diepgaande voorstudie thuis en onderzoekingen ter plaatse. Waarom niet een Nederlander ons dit boek schonk....

En ik dacht daarbij terug aan een artikel van Johan Koning, „Een en ander over koloniaal sentiment en over tropische atmosfeer", in Vragen van den Dag (XXXIX, 1924) verschenen, naar. aanleiding van Jean Galmot's kolonialen roman „Quelle étrange histoire....", waarin hij meedoogenloos constateert: „Wij Hollanders, zonen van een land, dat als derde koloniale mogendheid der wereld hoog staat aangeschreven, wij hebben blijkbaar een volksaard, die ons volkomen ongeschikt maakt, de „atmosfeer der tropen" te doorgronden, zelfs ook maar haar aan te voelen, zoodat men haar althans niet langer meer ietwat hooghartig zou kunnen ontkennen met een luide lofspraak op Hollandsche luchten en Hollandsche stemmingsimpressies".

Zou dit nog steeds moeten worden volgehouden?

En zou hij ook nu nog zonder tegenspraak mogen handhaven, hetgeen hij aan het slot van zijn artikel schreef: „Het schijnt, dat het zoogenaamde koloniale sentiment in het artistieke hart der Nederlandsche en zelfs der Nederlandsch-Indische schrijvers nog geen rol van beteekenis vervult"?

Bij welke vraag ik vanzelfsprekend buiten beschouwing houd den schrijver van onzen eigen bodem, Albert Helman, die trouwens niet valt onder de categorie van schrijvers, welke Johan Koning betrok in een vergelijking met Fransche schrijvers.

Het feit, dat een boek als DJUKA ons door een Amerikaan moest worden aangeboden en door vertaling onder het bereik moet worden gebracht van Nederlanders, die in hun eigen taal over eigen gebied over zee willen of moeten lezen, lijkt mij op mijn vraag bevestigend te antwoorden.

Paramaribo, November 1932. 